\title{
Public Health Operating Statistics
}

\author{
BY ROBERT G. WEBSTER, M.P.H.
}

“G OLD THAT BUYS health can never T be ill spent." Thus, in 1603, John Webster, Elizabethan poet and dramatist, gave expression to an opinion which later centuries have proved correct. The dividends of investments in health were never greater than they are today.

But today we must be prepared for a tightening of the purse strings. The cost of war or its prevention, estimated at over 75 percent of the total Federal budget (1), may have seriously threatened the future of the grants-in-aid fiscal program supported by the Congress. The nearness of the saturation point in the potential for tax collections in State and local governments indicates the need for better justification of public health programs, if increased support is to be expected from this source.

The generosity of the American people has made it possible for many voluntary organizations to make significant contributions to public health. Increasing efforts are required to collect such funds, and the number of voluntary groups competing for the beneficence of the public multiplies the problem of financing public health. If appropriating bodies are asked to provide adequate funds, public health agencies must provide standards for evaluation against which the funds requested may be measured. We should, therefore, thoughtfully consider the use of statistics to measure the costs of public health.

Robert G. Webster, M.P.H., is chief of the division of administration of the California State Department of Public Health. This paper was presented at the $2 d$ Conference on Public Health Statistics at the University of Michigan on June 17, 1952.

\section{Financial Evaluation}

Historically, the total gross cost of a unit of government was simply the total of the budgetary column. While this figure has some use as a general indication of the division of expenditures among the large areas of government service, more detail is needed to study the specific costs of a public health program. The recognition of a problem and the desire to do something about it are seldom sufficient in themselves to justify the grant of funds from the public treasury.

The use of statistics in building a vivid accounting picture of the operations of an agency well justifies the existence of a statistical service. Such an application of statistics gives real body to the substantiation and need for the statistical unit and presents opportunity for a realistic use of quantitative measurements in a situation where realism might be overlooked.

\section{Service Records}

"Service statistics in public health are numerical measurements of services rendered to individuals and to the community through pub-

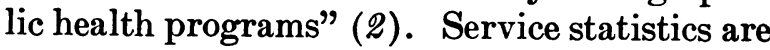
a measurement of activity in terms of number of units rather than in terms of dollars.

Service, operating, or performance statistics have real value in the analysis of public health programs. They serve as guides for the administration, for the measurement, and for the evaluation of activities, and for planning. It should not be overlooked, however, that service statistics, to serve their full purpose, should be related as far as practical to specific public health problems - the problems of population, water 
supply, sanitation, morbidity, mortality, and other factors.

Screening surveys, one of the newer activities in the public health field, furnish practical records in the fields of tuberculosis, venereal disease, and chronic disease. Operating records of these surveys often indicate the number of suspects found, suspects referred for medical followup, referrals completed, and the active or positive diagnoses resulting from the screening program. Statistics as to the number of persons screened are, of course, basic.

Records of persons immunized for diphtheria, pertussis, tetanus, smallpox, typhus, typhoid, or other diseases are another measure of the progressiveness and the activity of a public health agency. Such statistics usually are maintained by age groups. Often a separate tabulation is made of booster shots given.

The service records in communicable disease may be generally classified as records in the area of case finding and records related to control and service. The number of individuals X-rayed or the number of X-ray films used is an example of the case-finding statistic.

In the tuberculosis field, a tabulation of the number of tuberculosis contacts investigated becomes an evaluation of the case-finding activities. The number of laboratory tests made are of interest, too.

For control of service activities, it is helpful to compile a record of the clinic hours during which the clinic operates. This serves not only as an evaluation of the use of time, but it also indicates the availability of the service. The number of visits made to a clinic is the most frequently compiled operating statistic. More important, and more difficult, is the count of individuals admitted to a clinic which gives an opportunity for the evaluation of clinic coverage, rather than of only the clinic traffic.

Applicable to most public health programs is the tabulation of field visits or home visits. It cannot be overlooked in any cost study since in many activities a large proportion of the time is spent in home calls.

Operating records may be compiled in health education, although they are not always significant. The number of public health films shown and the number of people viewing them are tabulations which may be obtained with a min- imum of effort. Knowing the number of different training courses offered and the number of people exposed to such courses leads to an evaluation of a direct training enterprise. The number of pieces of printed material which are distributed is in itself not too meaningful, but a record of how many people read such literature, and of whether they are stimulated to seek health services, could be.

The obvious service statistics in the laboratory field are the number of various tests which are made. Upon refinement, such records will indicate test results in statistical form. An index to the efficiency of collection procedures and techniques is the number of specimens examined and whether they were received in a satisfactory condition.

A wealth of operating records has been accumulated in the area of sanitation. Here the basic index is the number of field visits made, usually tabulated by type of visit. Often the number of abatements accomplished is of value. Some environmental sanitation units maintain extensive statistical compilations. These are often justified because of the wide coverage of the assignments and responsibilities in sanitation.

The evaluation schedule (3) of the American Public Health Association is a notable contribution to service statistics. Although the schedule is geared primarily to measure problems and to provide an evaluation of services available in a health department, it has led many public health agencies to become conscious of the need for, and value of, regular statistical records of activities. An outgrowth of the evaluation schedule are health practice indexes which have caused many local communities to realize their inadequacies or perhaps their proficiency. There are doubtless other operating records meeting a specific need in public health. It should be pointed out that while tabulations of cases and deaths are basic to public health, they are essentially records of occurrence rather than records of activity.

\section{Problems of Compilation}

"What is a home visit?" is a seemingly simple question, but to define it so as to assure standardization is difficult. 
How does one record a partly completed procedure? Or what happens when the usual effort and time were expended in an activity, but there were no results? What happens when there were multiple accomplishments on one call? The accurate defining of geographic limits in the compilation of field service must be clear and concise: They must be understood if the statistics of operations are to reflect activities accurately.

\section{Standardization}

Ideally, the recording form should be one on which data may be quickly and easily recorded by a check mark without written explanation. Coupled with this ideal factor, however, is the seemingly contradictory need for adequate spacing and for clarity.

Attempts have been made to create standard forms of operating records. While experience is valuable in the preparation of forms, and while some day, perhaps, standard forms will be developed for definite purposes, it is probably naive to expect that the compilation of operating records can be standardized because of the variations in problems and in administration. Noteworthy, however, is the success which some States are now experiencing in statewide tabulations of selected data.

The publication in 1935 of "Recording of Local Health Work" (4) pointed the way to better forms in public health. Although the forms suggested therein did not always meet a specific need, the publication of the recommendations, which were developed through the cooperation of the Committee on Administrative Practice of the American Public Health Association, did emphasize the value of a consistent system of forms. It pointed up the value to be realized from careful planning and study of forms as an initial step in any record or statistics project.

\section{Too Much Detail}

Perhaps the greatest potential problem in the compilation of operating records is the temptation to gather too much detail and thus create a burdensome procedure. Operating records must be kept to the minimum of necessary data, or a Gargantuan procedure may result. The temptation to gather data affects nearly all.
It is so easy to speculate on what would be "nice to have," and let the items build up in the tabulations. Consideration of what practical use will be made of data should be foremost in the planning of operating statistics tabulations. The research worker may gather survey data on a sampling basis, or he may gather complete data during a limited period of time. Data which are only for information or for special purposes, or which have no application to administration or to the measurement or solution of a problem, should not be allowed to creep into permanent tabulations.

Then, too, the careful administrator will make certain that a statistical report does not become an end in itself. It is always possible for work to be done just for the benefit of the reports. To be justified, statistical data must be used.

\section{Financial Records}

Aid to the administrator in management of his organization is the primary objective of compiling cost data. Their most important use, administratively, is for period-to-period comparisons of performance costs for a particular activity. When costs increase significantly over those of an earlier period, investigation is suggested. If the increase in cost is justified and no action need be taken, it is often found that the increase may be caused by some factor which can be eliminated or corrected. Cost figures, therefore, are an indication of significant changes in program.

An administrator possessing valid financial information may choose which of two worthy programs will produce the most benefit when only a limited sum of money is available. Relative costs of each of several programs, particularly when units of service may be priced, are aseful in evaluating the work. Detailed program costs are of value in seeking special grants, for such requests must be predicated upon a preconceived project in which the anticipated cost must be stipulated.

Aid to more accurate budgeting is a second objective of a cost system. At best, it is diffcult to estimate in advance the financial requirements of an organization. In governmental budgeting it is often necessary to estimate expenditures as far ahead as 2 years. When costs 
are known and the quantity of work can be estimated, a unit cost may be applied to these estimates as a basis for arriving at the appropriations to be requested. There are limitations in the use of unit costs in budgeting, and such use may be found to represent a two-edged sword. Many activities in public health are intangible and cannot be easily measured by traditional workload statistics. Easily understood by budget officials are the elementary statistics of man-hours, units of performance, or, more specifically in city or State administration, the number of licenses issued, the number of miles of highway constructed, the number of beds maintained, or other measurable activities. But in public health administration, we must prepare budget substantiations with an intelligent use of statistics so as to reflect accomplishments and progress, or at least measure the extent of a problem.

A third objective of a cost project is to inform the public of the cost of public health. Such figures are often useful in answering questions or criticism. We are constantly faced with a need for emphasizing the economiès of prevention when the costs of prevention are compared with the costs of treatment.

Two general patterns are followed in the handling of governmental financial records. In one, which is commonly termed the line item budget, specific and separate appropriation is made for each individual job or group of jobs by organization units. Operating expenses and capital outlay for such units are also separately itemized, that is, a separate appropriation is made in each program for postage, telephone, printing, travel, and for all the various classes of operating expenses. A tabulation of expenditures against a line item budget produces a cost system of direct costs. If a unit were entirely self-contained, including all administrative expenses, the process of determining the cost of the program would be greatly simplified.

Such, however, is rarely true.

The other general plan of budgeting is through means of a blanket appropriation for the total operation. It may be implemented by a cost accounting system wherein each item of salary and expenditure is charged to certain programs or functions. The appropriations are justified by estimates based on previous experience and costs. In this pattern, costs are developed on a cumulative basis month-bymonth.

However, the fiscal systems of most governmental agencies are a combination of these two general patterns, in varying degrees. One complication is that many of the personnel in public health agencies are engaged in generalized programs, rather than in specialized services. Nurses, for example, are involved in many or in the entire gamut of public health activities.

\section{Other Record Needs}

A new need for cost figures in public health operation has arisen for insuring the validity of categorical grant expenditures. The Public Health Service and the Children's Bureau have found it desirable to request much more detail from States in justification of congressional appropriations. The problem arises because through generalized services, the same personnel will work in the fields represented by more than one Federal grant.

For example, it is proposed in some situations to assign a unit cost to a nursing visit, based on a time and a cost study. Others will assign a unit cost to units of service, such as an immunization, or a clinic visit. In the laboratory field, validity can be verified by using the number of examinations of various kinds multiplied by the unit cost per specimen. Such unit cost can be determined either by an analysis in the laboratory or by accepting other cost data.

The need for justification of expenditures further underlines the desirability of greater attention to costs in public health agencies generally.

\section{Unit Costs}

In determining the costs of an activity in a generalized operation, the allocation of personnel time or salaries looms as the most important single factor. The problem is essentially one of the division of an individual's time on a basis of hours spent on the particular programs, and segments of programs, which he serves. 


\section{First Opinions, Then Observations}

\section{... Now Measurement and Analysis}

\section{-from remarks by Dr. Haven Emerson at the summary session of the Second Conference on Public Health Statistics}

In the beginning there were ideas and opinions, then observations, and these led to measurements, and this required numbers which led the mind of man from fingers to stellar spaces and predictions of eclipses. Facts and records, once accepted, tempted minds into their logical deductions, so arithmetic and logic grew together and have been inseparable.

Whether for war or slave labor, man was counted in early times, and distances were measured on land and sea and in the heavens. Our common interest has been in the human family and its social aggregates, their origin, growth, and decay, and the causes of these. Our first early concern was with reproduction of our kind and their survival, and only in today's times is there concern with their endurance, with quality and content of life.

As the first job of the physician was with the sick, the first concern of the health officer was with loss of life and with known preventable causes. He was a lone soul crying in a wilderness of disease. He sought to prevent, and thereby assumed society's heaviest burden. He aimed at the demos, the socius, rather than at homo, the man. He was government's early agent of the biological sciences, the community guardian against the errors of inheritance, environment, and acquired habits of work, shelter, food, play, and reproduction.

Today he is a symbol of that composite branch of local government, the health department. He is not a person, but the personification of a group of specialist professions and technologies - physician, engineer, nurse, laboratory director, epidemiologist, statistician, educator, dentist, and veterinarian.

Permit me to recall the fact that health departments have been created to avert preventable diseases, to protect the community against factors of environment affecting health, to teach the laws of human biology so that longer, deeper, broader lives can be assured and not merely survival of the babe. Care of the sick is best done by a physician sought by the person in need of prevention, diagnosis, and treatment. The health department is a multiprofessional team, and in that team the statistician is an incorruptible bulwark against bungling in life-saving and life-giving services.
Public health personnel are highly trained professionally. They are attuned to educational and research work, but often they are unfamiliar with the record requirements of a production operation. While it is relatively simple in a manufacturing plant to determine with a stopwatch the time taken on an assembly line for each of many detailed operations, the stopwatch application is seldom appropriate to public health time studies.

Simple time studies may often be made in laboratory or in vital statistics procedures. In laboratories, a specific time usually may be established for each operation, and the beginning and ending points of such a function are rather clearly defined. They are less clear in 
the routine recording of vital statistics data where the staff member must do a certain amount of interpreting, as the recording function is only partly mechanical. Beyond this, most public health operations are not routine but require deliberation, and thus an arbitrary evaluation in terms of time is difficult.

Nevertheless, reasonably satisfactory data may be accumulated in determining the standard or average time which an activity takes. A broad base is one safeguard to assure the validity of such data. Surveys to determine the average time required in a particular type of field visit should cover a long enough period so that seasonal effects will be truly reflected, and so that the extremes will be considered.

In determining personnel costs, other factors besides direct time must be considered : the cost of vacation salaries, of overtime, of retirement, and of office time occupied in conferences, in meetings, and in report writing. A special problem in time allocation is the handling of the travel time which an individual spends in transportation as distinguished from the cost of transportation.

To conduct a continuous record of time accounting becomes burdensome and not very fruitful. Surveys, special studies, or sampling techniques are an answer to the problem of record keeping.

Operating expenses form the next general component of the financial costs of a program. Here we find the actual costs of travel and transportation, as well as costs of supplies, laundry, stationery, forms, postage, and the many other necessary continuing expenses. General overhead includes such items as office rent, utilities, telephone, furniture, professional expenses, and other related items. These costs must all be considered on an appropriate pro rata in the total program cost.

The National Organization for Public Health Nursing carried on studies of the detailed costs in public health nursing since 1922 and provided methods of cost accounting whereby a nursing service may easily determine its costs. Part of its pioneering work was the development of a time study work sheet which accounts for a nurse's time in three categories: first, the "component," which is travel, preparation, or the activity itself; second, the "cost center," or the type of activity which was conducted-a visit, a clinic, a school, group teaching, and related functions; and third, the "service," which is the program in which the nurse is engaged, such as infant health, tuberculosis, acute communicable disease, or others. The time of the nurse is divided; each unit of time shows all three elements.

For a time study to be valid, all time of personnel must be accounted for, so that the total allocated cost will add up to the total expenditures. This often requires the recording of unproductive time, and sometimes the accounting itself serves to encourage full production. Again, it is worth emphasizing that the problems of time recording in public health are much more complex than they are in simple production activities. For example, in an automobile repair shop a mechanic will stamp the time he begins the job and the time he ends the job on each job ticket, and the customer pays for all time between such recordings. While this is the theory applied to time studies in public health, it is much more difficult to put into practice.

A good reason for determining unit costs in some situations is to provide an appropriate basis for charging or billing the recipient of the service, as illustrated in the management of a hospital, or in a visiting nurse function. This element is usually lacking in public health activities.

Detailed costs, however, are not always necessary for good administration. Costs should be determined only when they are needed. A tabulation of the number of units of performance is often the only computation justifiable as an aid to administration. Care must be taken that the cost and statistical procedures do not build up so that they occupy more time than is necessary. Cost figures are of diluted value unless they are promptly recorded and are available. Timeliness of such data is exceedingly important if they are to be properly used.

Great care must be exercised in attempting to compare costs between several agencies. Because so many variables exist, comparisons must be thoroughly explored. Travel time in urban areas differs from rural areas. Differences in salary rates, in the purchasing value of the 
dollar, and in the services available and the plans of operation make large variations in program costs. The same methods must be followed between various agencies if comparisons are to be made. Comparisons of costs are often deceptive if they are lifted out of context and compared without careful analysis.

\section{Summary}

Operating statistics may be a valuable aid to determining program costs. While the gross cost of a program may be estimated from some budgetary statements, in a generalized public health operation statistics are necessary to properly segregate such costs by program.

Statistics as to service or performance units are a basic element in public health administration, having much value for administrative, budgetary, and educational purposes. In many situations, it is unnecessary to perform the additional computations to determine the financial costs.

The time which each individual service activity requires can best be determined by surveys, studies, or sampling. Continuous routine reporting of detailed time breakdown should be avoided.
There are many hazards in the statistical procedures leading to the computation of program costs, but the principal one is the temptation to allow the reporting and recording procedures themselves to become arduous and unduly complicated.

The detail of cost data to be accumulated should be dictated by the needs for it. Excess tabulation of cost data should be avoided, since for many purposes the statistical data alone may be used profitably, without the dollar figures.

\section{REFERENCES}

(1) Staats, Elmer B.: Health and hospital programs in the Federal budget. Pub. Health Rep. 67: 164-169 (1952).

(2) Public Health Conference on Records and Statistics. Proceedings 1950. Washington, D. C., National Office of Vital Statistics. Processed. p. 12.

(3) American Public Health Association: Committee on administrative practice. Evaluation schedule (for use in the study and appraisal of community health programs). New York, The Committee, 1947.

(4) Walker, W. F., and Randolph, C. R.: Recording of local health work. New York, The Commonwealth Fund, 1935.

\section{Statistics and Statistical Methods in Public Health Practice}

With this issue, Public Health Reports completes publication of 16 papers presented in June 1952 before the Second Conference on Public Health Statistics at the School of Public Health, University of Michigan. These papers, with a number of others, are to be assembled in a one-volume proceedings and will be available from the school at Ann Arbor. Listed below are the papers in the order in which they were published:

Vistas in public health statisticsby Clarence J. Velz, August 1952, pp. 725-728

Application of statistical analysis in a health program-by Ruth $\mathbf{R}$. Puffer, August 1952, pp. 729-736

Current methods of collecting statistics of health and health problems-by O. K. Sagen, August 1952, pp. $737-740$
Statistics in the administration of a State health department-by John D. Porterfield, August 1952, pp. 741-746

The administrative value of statistics to $a$ local health officer-by Berwyn F. Mattison, August 1952, pp. 747-754

Needed improvements in mortality data-by Iwao M. Moriyama, September 1952, pp. 851-856

The survey approach to morbidity and health data-by Halbert $\mathrm{L}$. Dunn, October 1952, pp. 998-1002

Sampling and field procedures of the Pittsburgh morbidity survey-by Daniel G. Horvitz, October 195:, pp. 1003-1012

The sampling of records-by Robert E. Patton, October 1952, pp. 10131019

Entomological survey methods-by Robert E. Serfling, October 1952, pp. 1020-1025
A sample survey of home injuriesby F. M. Hemphill, October 1952, pp. 1026-1034

Usefulness of communicable disease reports-by Ida $L$. Sherman and Alexander D. Langmuir, December 1953, pp. 1249-1257

Birth statistics in maternal and child health programs-by William Haenszel, January 1953, pp. 71-80

Statistics in a health department medical care plan-by Matthew Taback and Huntington Williams, February 1953, pp. 157-166

Public health operating statisticsby Robert G. Webster, May 1953, pp. $467-473$

First, opinions, then observations ... Now measurement and analysisfrom remarks by Dr. Haven Emerson at the summary session of the Second Conference on Public Health Statistics, May 1953, p. 471 